\title{
First Comparative Analysis of the Simultaneous Horizontal Wind Observations by Collocated Meteor Radar and FPI at Low Latitude through 892.0-nm Airglow Emission
}

\author{
Shengyang Gu ${ }^{1,2, *}$, Xin Hou ${ }^{1}$, Na Li ${ }^{2,3}$, Wen $\mathrm{Yi}^{4}$, Zonghua Ding ${ }^{2,3}$, Jinsong Chen ${ }^{2,3}$, Guoyuan Hu ${ }^{1}$ \\ and Xiankang Dou ${ }^{1}$
}

1 Electronic Information School, Wuhan University, Wuhan 430072, China; 2015301200088@whu.edu.cn (X.H.); hgy@whu.edu.cn (G.H.); dou@ustc.edu.cn (X.D.)

2 National Key Laboratory of Electromagnetic Environment, China Research Institute of Radio-Wave Propagation, Qingdao 266000, China; lina861@mail.ustc.edu.cn (N.L.); zhdingmou@163.com (Z.D.); myuts@icloud.com (J.C.)

3 Kunming Electro-Magnetic Environment Observation and Research Station, Qujing 655000, China

4 Key Laboratory of Geospace Environment, Chinese Academy of Sciences, University of Science \& Technology of China, Hefei 230026, China; yiwen@ustc.edu.cn

* Correspondence: gushengyang@whu.edu.cn; Tel.: +86-15755142316

check for updates

Citation: Gu, S.; Hou, X.; Li, N.; Yi, W.; Ding, Z.; Chen, J.; Hu, G.; Dou, X. First Comparative Analysis of the Simultaneous Horizontal Wind Observations by Collocated Meteor Radar and FPI at Low Latitude through 892.0-nm Airglow Emission. Remote Sens. 2021, 13, 4337. https:// doi.org/10.3390/rs13214337

Academic Editor: Simone Lolli

Received: 12 August 2021

Accepted: 25 October 2021

Published: 28 October 2021

Publisher's Note: MDPI stays neutral with regard to jurisdictional claims in published maps and institutional affiliations.

Copyright: (c) 2021 by the authors. Licensee MDPI, Basel, Switzerland. This article is an open access article distributed under the terms and conditions of the Creative Commons Attribution (CC BY) license (https:// creativecommons.org/licenses/by/ $4.0 /)$.

\begin{abstract}
The Fabry-Pérot interferometer (FPI) and meteor radar are two important techniques for measuring the horizontal wind field in mesopause region, the observations of which still lack comprehensive comparison. Kunming Observatory $\left(25.6^{\circ} \mathrm{N}, 103.8^{\circ} \mathrm{E}\right)$ has deployed both instruments in recent years and provides collocated meteor radar and FPI observations. The meteor radar measures the horizontal wind fields over 24 hours every day continuously, whereas the FPI can only work during the night with clear air condition. FPI horizontal wind data from the 892.0-nm airglow emission (with a peak height at $\sim 87 \mathrm{~km}$ ) from 26 January to 8 February 2019 were comparatively analyzed with simultaneous meteor radar observations, which cover the range between 80 and $90 \mathrm{~km}$ with a vertical resolution of $1.8 \mathrm{~km}$. It was found that the temporal variations in the horizontal wind fields observed by the FPI and meteor radar were generally consistent with one another, with the highest 2-D correlation coefficients of $0.91(0.88)$ at $88(87) \mathrm{km}$ for the meridional (zonal) wind, which agreed with the peak height of $\mathrm{OH}$ airglow emission observed by the TIMED/SABER instrument. In addition, the correlation coefficient for the weighted meteor radar horizontal wind by $\mathrm{OH}$ concentration between 86 and $88 \mathrm{~km}$ and 85 and $89 \mathrm{~km}$ increased slightly from $0.91(0.89)$ to 0.92 (0.89) for the meridional (zonal) wind, which indicated the contribution of $\mathrm{OH}$ concentration beyond the peak height to the FPI wind observations. We also found that the absolute horizontal wind values detected by two instruments were linearly correlated with a slope of $\sim 1.3$ for both wind components, and meteor radar wind observations were usually larger than the FPI observations.
\end{abstract}

Keywords: mesospheric horizontal wind; FPI; meteor radar

\section{Introduction}

The mesosphere and lower thermosphere (MLT) region lies between 60 and $140 \mathrm{~km}$ above the Earth, where many atmospheric waves amplify and break [1]. The wave-mean flow interaction maintains the momentum and energy equilibrium in the MLT region, which shows a pole-to-pole residual circulation from the summer to winter hemisphere [2]. The detection of the meteorological field is, thus, significant to the dynamic research in the MLT region [3-6], because neutral wind and temperature play vital roles in the dynamics and energy transmission $[7,8]$.

The use of meteor radar equipment is one of the most effective methods to measure the neutral wind in the MLT region between 70 and $110 \mathrm{~km}$ according to the Doppler shifts of a coherent signal, which effectively represent the radial velocities and positions of 
meteor trails. Meteor radar is capable of operating day and night all year round, regardless of the weather conditions, and, thus, is broadly utilized in mesospheric dynamic studies [9-12]. Currently, the horizontal wind observations from meteor radar are extensively utilized in the study of dynamics in the MLT region between 80 and $100 \mathrm{~km}$. For example, meteor radars in Mohe, Beijing, and Wuhan were utilized to study the quasi-10-day waves (Q10DW) in the MLT area during the SSW in February 2018 [13], and the authors found that the enhancement of Q10DW was intimately related to the SSW event. Additionally, the nonlinear interaction between the quasi-2-day wave and tides was also investigated with meteor radar observations at Maui $\left(20.8^{\circ} \mathrm{N}, 156.4^{\circ} \mathrm{W}\right)$, which showed clear child waves with periods between $16 \mathrm{~h}$ and $9.6 \mathrm{~h} \mathrm{[14]}$.

The FPI is a passive optical detection instrument that is sensitive to light [15], which can only work at night with clear air condition. The FPI can measure the wind field at the height of the airglow radiation by recording the Doppler shift of a specific wavelength. For example, the 557.7-nm and 630.0-nm airglow emission from $\mathrm{O}_{1}$ could be utilized to track the neutral wind at $\sim 97$ and $\sim 250 \mathrm{~km}$, respectively. Moreover, the 892.0-nm airglow emission from $\mathrm{OH}$ reflects the neutral wind at $\sim 87 \mathrm{~km}$. The FPI thermospheric wind fields from the 630.0-nm airglow emission over the Asian and American continents were compared [7] and the authors found that the reversal time of the zonal wind was earlier at Millstone Hill $\left(42.6^{\circ} \mathrm{N}, 71.5^{\circ} \mathrm{W}\right)$ than at Kelan $\left(38.7^{\circ} \mathrm{N}, 111.6^{\circ} \mathrm{E}\right)$. The authors of [16] studied the influences of sudden stratospheric warming and planetary waves on the MLT temperature and neutral wind based on the 557.7-nm channel FPI observations, which were found to be equally strong. Moreover, the semiannual and triannual oscillations were identified by the FPI observation at a mid-latitude location $\left(53.5^{\circ} \mathrm{N}, 122.3^{\circ} \mathrm{E}\right)$ [17].

Comparisons between the wind observations by FPI and meteor radar have been reported in recent years. For example, the FPI wind observations over Kelan $\left(38.7^{\circ} \mathrm{N}, 111.6^{\circ} \mathrm{E}\right)$ were also compared with meteor radar wind observations over Beijing $\left(39.98^{\circ} \mathrm{N}, 116.37^{\circ} \mathrm{E}\right)[18,19]$. The authors found that the correlation coefficient between these two types of winds reached 0.95 and 0.90 at $87 \mathrm{~km}$ for meridional and zonal wind, respectively, which is slightly larger than the correlation coefficients at $97 \mathrm{~km}$. The authors of [20,21] further compared the FPI and meteor radar at King Sejong Station in the Antarctic Peninsula $\left(62.22^{\circ} \mathrm{S}, 58.79^{\circ} \mathrm{W}\right)$, which also showed correlation coefficients between 0.8 and 0.95 for the $\mathrm{OH} 892.0-\mathrm{nm}$ airglow emission, but varied from year to year. Additionally, the amplitudes of the FPI wind observations were $\sim 0.71$ and $\sim 0.78$, as large as the amplitudes of the meteor radar wind observations at $87 \mathrm{~km}$ for zonal and meridional components, respectively.

However, the comparisons between the FPI and meteor radar wind at low latitude have not been performed. In this paper, we compared the neutral wind data observed by an FPI at a low-latitude location $\left(25.6^{\circ} \mathrm{N}, 103.8^{\circ} \mathrm{E}\right)$ with that simultaneously measured by a collocated meteor radar, which contributes to the previous works performed for the high-latitude King Sejong Station $\left(62.22^{\circ} \mathrm{S} 58.79^{\circ} \mathrm{W}\right)[20,21]$ and mid-latitude Kelan Station $\left(38.7^{\circ} \mathrm{N}, 111.6^{\circ} \mathrm{E}\right)[18,19]$ FPI observations. Additionally, both the temporal variations and the absolute values between these two instruments were comparatively investigated. The FPI and meteor radar instrument data sets are described in Section 2. A comparative analysis of the two observations is presented in Section 3, followed by a summary in Section 4.

\section{Date Descriptions}

\subsection{Meteor Radar}

The Kunming Stratospheric-Tropospheric (ST) meteor radar has been operating since 2008 , at a frequency of $53.1 \mathrm{MHz}$ and peak power of $40 \mathrm{~kW}$, which is similar to that described by previous work [22,23]. The Kunming meteor radar is operated by the China Research Institute of Radio Wave Propagation (CRIRP), belonging to the ATRAD meteor detection radar (MDR) series, and is essentially the same as that described by [24]. The system parameters are summarized in Table 1. 
Table 1. Main operation parameters of the Kunming meteor radar.

\begin{tabular}{cc}
\hline Frequency & $53.1 \mathrm{MHz}$ \\
\hline Peak power & $40 \mathrm{~kW}$ \\
\hline Pulse repetition frequency & $430 \mathrm{~Hz}$ \\
\hline Coherent integrations & 4 \\
\hline Range resolution & $1.8 \mathrm{~km}$ \\
\hline Pulse-type & Gaussian \\
\hline Pulse width & $24 \mu \mathrm{s}$ \\
\hline Duty cycle & $15 \%$ \\
\hline Detection range & $70-110 \mathrm{~km}$ \\
\hline
\end{tabular}

Figure 1a shows the number of meteors detected by the meteor radar at the Kunming Observatory from day 26 to 39 in 2019 . Meteors were detected from $74 \mathrm{~km}$ to $98 \mathrm{~km}$, but the area with the most meteors was distributed from 78 to $90 \mathrm{~km}$. Figure $1 \mathrm{~b}$ is the average number of meteors at various altitudes during this period. Generally, the peak meteor height distribution observed by the 53.1-MHz meteor radar during the winter was close to $87 \mathrm{~km}[23,25]$. The average numbers of meteors from 76 to $98 \mathrm{~km}$ were more than 10 per hour, and the average number of meteors at $86 \mathrm{~km}$ reached $\sim 43$ per hour.

(a) Count of meteors per hour

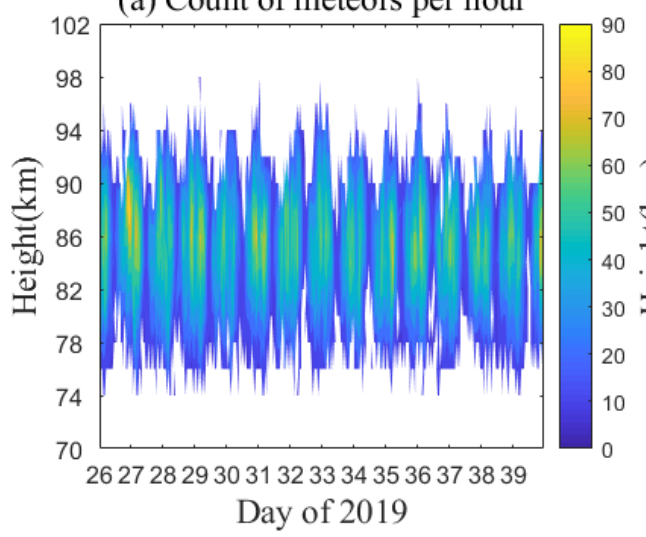

(b) Average count of meteors per hour

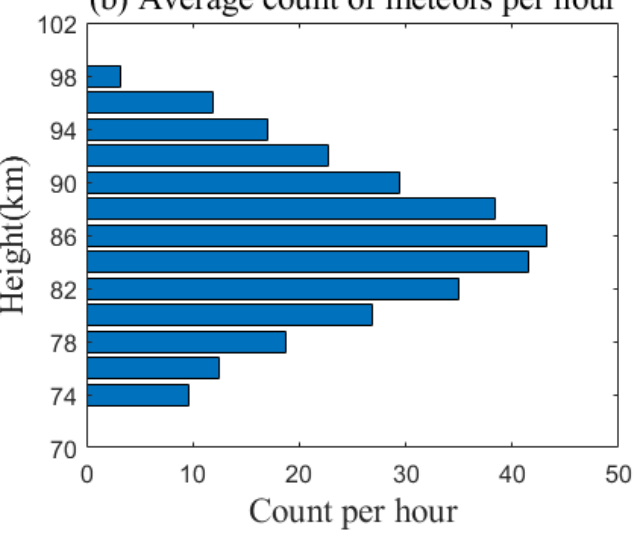

Figure 1. (a) The number distribution of meteors detected by meteor radar in the height range of 70-102 km with a temporal resolution of 1 hour, (b) the average number of meteors at each altitude during this period.

Figure 2 shows the meridional wind measurements from 80 to $90 \mathrm{~km}$ observed by the Kunming meteor radar from 26 January to 8 February. The southward wind was from 4:00 to 20:00 UT every day at $\sim 90 \mathrm{~km}$ and reached a maximum value of $150 \mathrm{~m} / \mathrm{s}$ on 29 January. The phases of the southward wind propagated downwards over time. The northward wind at $90 \mathrm{~km}$ appeared between 20:00 and 4:00 UT every day, and its phase also propagated downward over time. Figure $2 b$ shows the zonal wind, which was the strongest at $\sim 90 \mathrm{~km}$ and 0:00 UT every day. The maximum zonal wind reached as large as $130 \mathrm{~m} / \mathrm{s}$. Additionally, the eastward and westward winds reached their maximum at approximately 6:00 and 20:00 UT every day, respectively. 

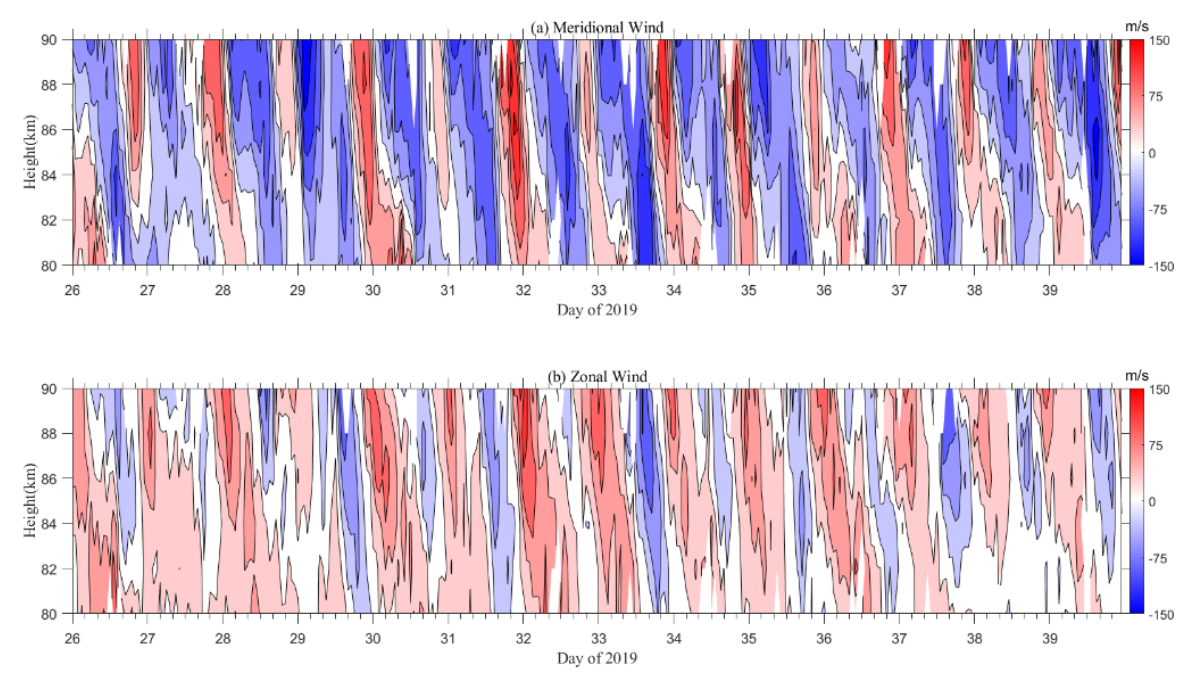

Figure 2. (a) is the meridional wind from $80 \mathrm{~km}-90 \mathrm{~km}$ height observed by meteor radar in Kunming Observatory from 26 January to 8 February 2019 , and (b) is the zonal wind.

\subsection{FPI}

The Kunming FPI observes airglow emissions to measure neutral winds from the upper mesosphere $(\sim 87 \mathrm{~km})$ to the middle thermosphere $(\sim 250 \mathrm{~km})$ with clear air conditions. Due to the strong background sunlight during the day, the FPI can only work at night. FPI is mainly composed of a sky scanner, a filter wheel, an etalon chamber, a focal lens, a CCD, and a thermostat. The scanning turntable is the scanning control part of the sky scanner. The horizontal azimuth and elevation angles are adjusted by a stepping motor automatically controlled by the software to generate a total of five azimuths, including east, west, north, south, and up. The elevation angle is $45^{\circ}$ for the east, west, north, and south. It takes $\sim 10 \mathrm{~min}, \sim 10 \mathrm{~min}$, and $\sim 20 \mathrm{~min}$ for channels of $892.0 \mathrm{~nm}, 557.7 \mathrm{~nm}$, and $630.0 \mathrm{~nm}$, respectively. The wind fields, thus, have a time resolution of $\sim 40 \mathrm{~min}$. The airglow signal enters the front-end optical receiving system through the turntable channel and enters the filter wheel after collimating the optical path. The filter wheel is equipped with three filters, which can pass light of $557.7 \mathrm{~nm}, 630 \mathrm{~nm}$, and $892 \mathrm{~nm}$ that correspond to $\sim 97 \mathrm{~km}, \sim 87 \mathrm{~km}$, and $\sim 250 \mathrm{~km}$, respectively. The filter wheel rotates to make the three filters work in cycles. The etalon is mainly composed of two parallel high-reflectivity smooth glasses. The optical signal enters the etalon after passing through the filter and continuously reflects between the two parallel glasses to form an interference ring. The thermostat is responsible for maintaining the temperature of the etalon and reducing the deformation of the etalon due to temperature changes. After the optical signal passes through the etalon, it is converged on the CCD to obtain the final interference ring image. The wind speed can be inverted by calculating the radius of the interference ring in each image.

Figure 1 shows that the detection of the Kunming meteor radar between 80 and $90 \mathrm{~km}$ is nearly continuous for 24 hours every day. This paper will only compare the meteor radar horizontal wind observations with the 892.0-nm FPI observations, since the $892.0-\mathrm{nm}$ FPI observations measure wind velocities at $87 \mathrm{~km}$ on average. Figure 3 shows the 892.0-nm FPI observations from 26 January to 8 February with the meridional and zonal wind observations exhibited by Figure 3a,b, respectively. Figure 3a shows that the meridional wind was a northward wind throughout the 27th day of 2019. The northward wind speed was approximately $10 \mathrm{~m} / \mathrm{s}$ at 13:00 UT, and then increased, reaching $72 \mathrm{~m} / \mathrm{s}$ at 21:00 UT. On the 31st day, at 13:00UT, the southward wind was $25 \mathrm{~m} / \mathrm{s}$, after which the wind speed decreased to 0 , and then turned to a northward wind at approximately 14:00 UT and continued to increase, reaching the maximum value of $125 \mathrm{~m} / \mathrm{s}$ at 18:00 UT. The wind speed then decreased, dropping to $43 \mathrm{~m} / \mathrm{s}$ at 23:00 UT. The meridional wind field changes in the remaining days were similar to the 31st day: All were southward winds at 13:00 UT, and then the wind speed decreased to 0 , turning into a northward wind and 
increasing continuously, reaching the peak at approximately 19:00 UT, after which the wind speed continued to decrease.

(a) Meridional wind

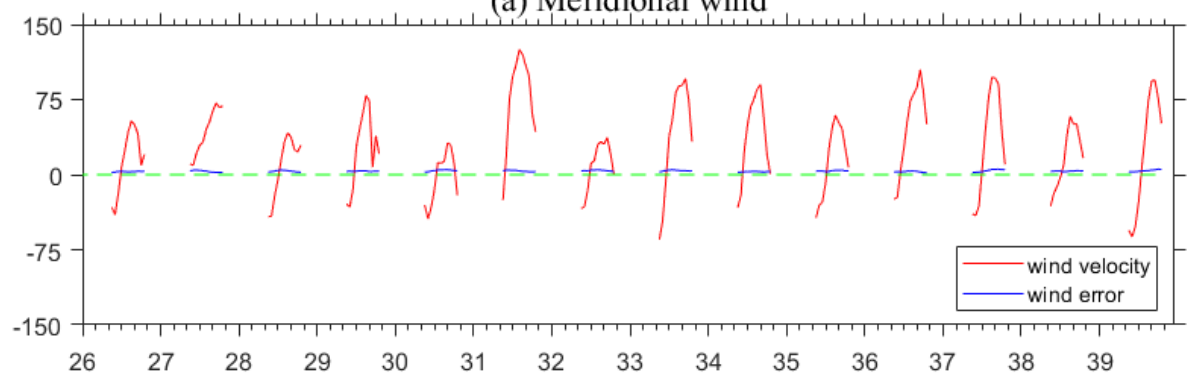

(b) Zonal wind

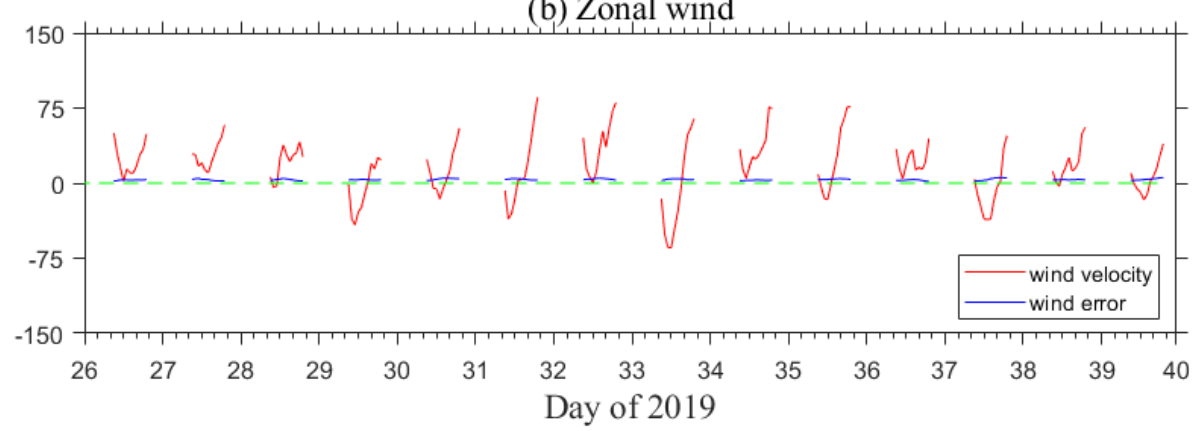

Figure 3. The FPI (a) meridional and (b) zonal wind field in $\mathrm{m} / \mathrm{s}$ at $\sim 87 \mathrm{~km}$ during days $26-39$.

Figure $3 \mathrm{~b}$ shows the zonal wind observations during days $26-39$ by the FPI $892.0-\mathrm{nm}$ channel, which represents the wind at $\sim 87 \mathrm{~km}$ with a temporal resolution of $\sim 40 \mathrm{~min}$. The observed zonal wind at $87 \mathrm{~km}$ showed a decreasing tendency, firstly, which then increased after a minimum value. For example, the eastward wind speed was approximately $\sim 50 \mathrm{~m} / \mathrm{s}$ at 13:00 UT on day 26 , which dropped to $\sim 2 \mathrm{~m} / \mathrm{s}$ at 17:00 UT. The wind speed started to increase after that and reached the maximum value of $50 \mathrm{~m} / \mathrm{s}$ at 23:00 UT. The trend of the zonal wind on day 27 was mostly similar to that on day 26 . The eastward wind speed was $\sim 29 \mathrm{~m} / \mathrm{s}$ at 19:00 UT and then decreased to a minimum value of $11 \mathrm{~m} / \mathrm{s}$ at 19:00 UT. After that, the wind speed kept rising and reached $94 \mathrm{~m} / \mathrm{s}$ at 23:00 UT. Nevertheless, the zonal wind exhibited day-to-day variabilities. For example, the zonal wind decreased and increased repeatedly on days 28,36 , and 38 . The eastward zonal wind reached the greatest value of $\sim 75 \mathrm{~m} / \mathrm{s}$ on day 31 , while it was only $\sim 10 \mathrm{~m} / \mathrm{s}$ on day 29 . The westward wind reached a minimum value of $\sim-75 \mathrm{~m} / \mathrm{s}$ on day 33 , while the zonal wind was always eastward on days 26, 27, and 36. We compare the horizontal wind observations by the FPI 892.0-nm channel with the meteor radar observations during the same time in the next section.

\section{Comparison and Discussion}

Figure 4 compares the meridional wind at $\sim 87 \mathrm{~km}$ observed by the FPI $892.0-\mathrm{nm}$ channel and meteor radar during days 26-39. The temporal variations in the meridional wind observed by FPI and meteor radar were generally consistent with each other. For example, the meridional winds reached the maximum value on days $27,29,31,33$, and 36. The meridional wind was mostly northward at midnight, and the strongest meridional wind occurred at $~ 02: 00 \mathrm{UT}$. We note that the meridional wind observations of the meteor radar were relatively larger than those observed by FPI regardless of the wind directions. In the zonal direction, the temporal variations in the FPI and meteor radar observations were also generally similar. The FPI observations were also smaller than the meteor radar observations, which were exhibited by the meridional wind from 13:00 to 17:00 UT on days $29,31,33$, and 37 , and at 23:00 UT on days $28,29,30,31$, and 32. 
(a) FPI Meridional Wind

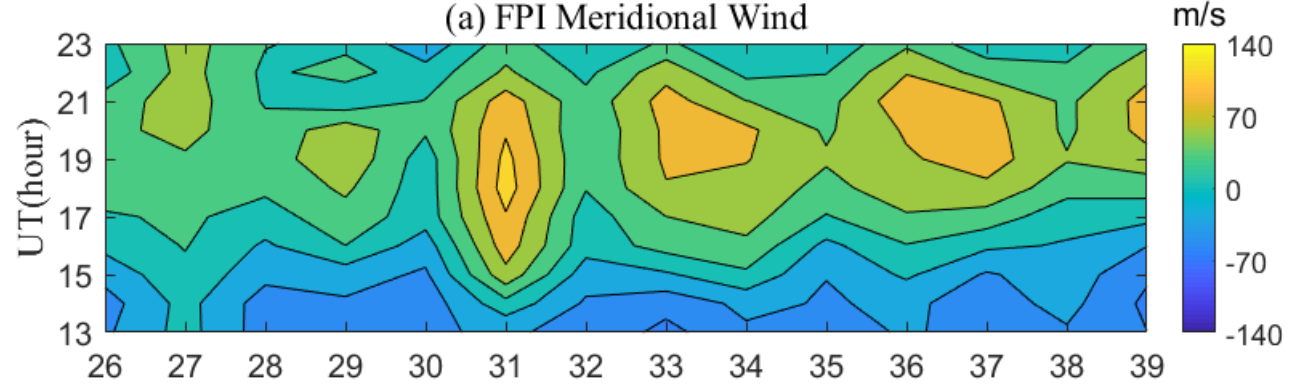

(b) MR Meridional Wind $(87 \mathrm{~km})$

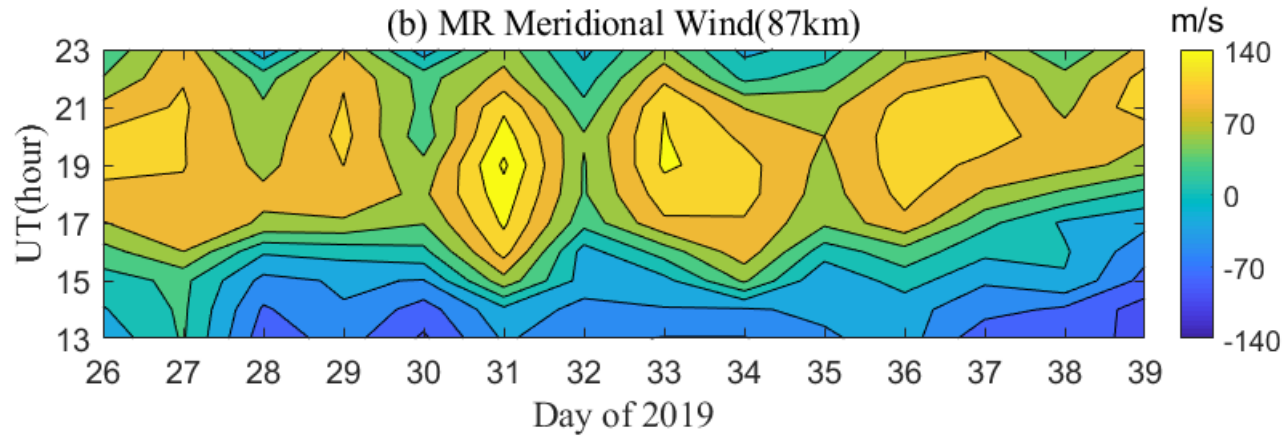

Figure 4. Comparison of the meridional wind observed by (a) FPI and (b) meteor radar at $87 \mathrm{~km}$.

To study the relationship between the temporal variations in the FPI and meteor radar horizontal winds, we performed a two-dimensional correlation analysis on the wind data sets presented in Figures 4-6 shows the temporal correlation coefficients between the FPI and observations and meteor radar observations during days 26-39 at different heights. Note that the meteor radar has a vertical resolution of $1.8 \mathrm{~km}$, and the wind values at every height are estimated by accounting for all the meteors in a $1.8-\mathrm{km}$ grid. In the zonal direction, the correlation coefficient between the FPI and meteor radar winds reached a peak of 0.88 at $87 \mathrm{~km}$, which is only slightly larger than the correlation coefficient of 0.87 at $86 \mathrm{~km}$. The correlation coefficients decreased significantly below $86 \mathrm{~km}$ and above $87 \mathrm{~km}$ with values of only $0.77,0.83$, and 0.78 at 85,88 , and $89 \mathrm{~km}$, respectively. In the meridional direction, the correlation coefficient reached the highest value of 0.91 at $88 \mathrm{~km}$, which is slightly higher than the peak height of $87 \mathrm{~km}$ for the zonal component. At $87 \mathrm{~km}$, the correlation coefficient for the meridional wind was $\sim 0.9$, which is also larger than the value of 0.88 for the zonal component at the same height. Moreover, the correlation coefficients for the meridional wind component at $85,86,89 \mathrm{~km}$ were $\sim 0.75, \sim 0.84$, and 0.86 , respectively. The meridional wind component had a better correlation relationship than the zonal component. Generally speaking, our results are similar to those achieved by the authors of [20], who compared the FPI and meteor radar observations at a highlatitude observatory (King Sejong Station (KSS), $\left(62.22^{\circ} \mathrm{S}, 58.79^{\circ} \mathrm{W}\right)$ ). They showed that the correlation between the meteor radar and FPI at KSS were 0.88 and 0.92 for the meridional and zonal wind components, respectively, which generally agrees with our analysis results. However, the authors of [21] showed that the correlation coefficients were only 0.28 for the zonal wind and 0.36 for the meridional wind at $87 \mathrm{~km}$ at KSS by analyzing the FPI and meteor radar observations during 2017, which is much smaller than the coefficients in our analysis. Currently, we are not sure about reasons for the discrepancy. 
(a) FPI Zonal Wind

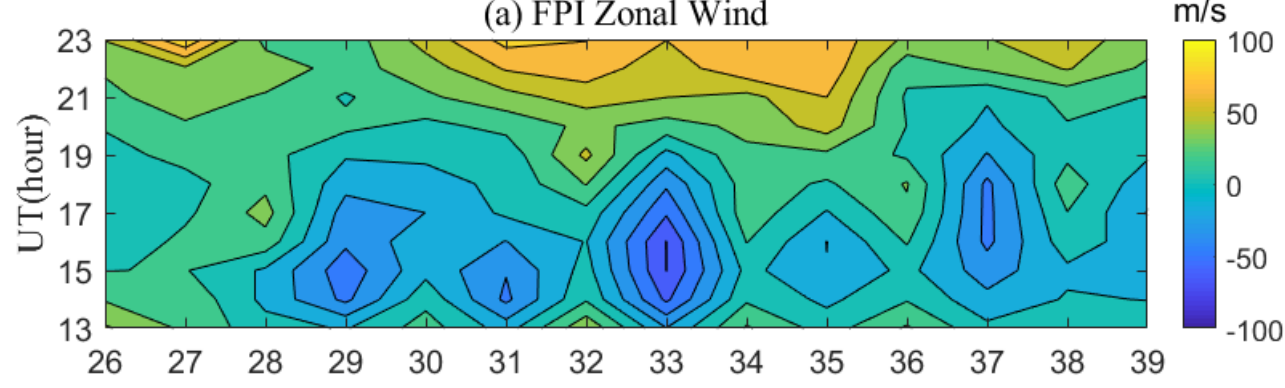

(b) MR Zonal Wind $(87 \mathrm{~km})$

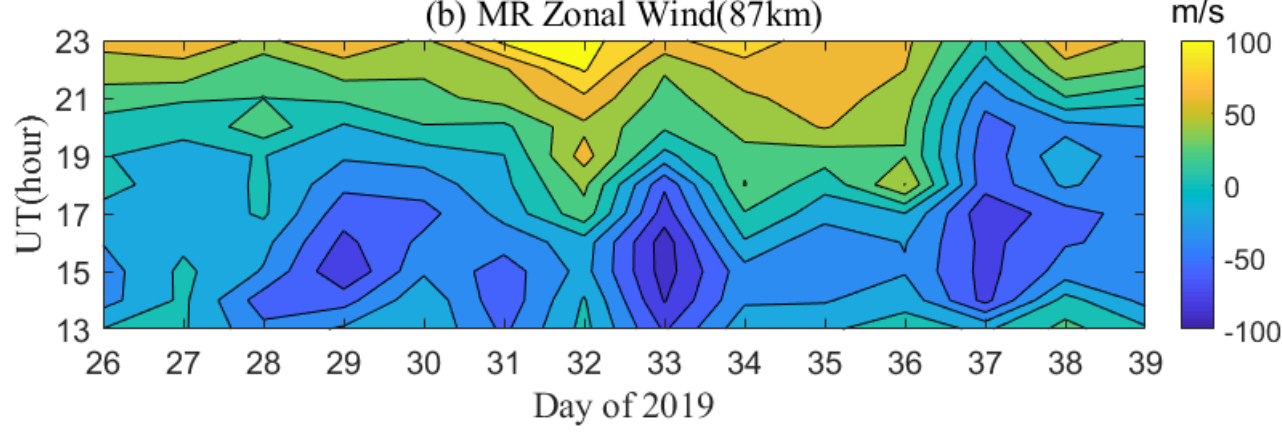

Figure 5. The same as Figure 4 but for the zonal wind component. (a) FPI and (b) meteor radar.

(a) Meridional Wind

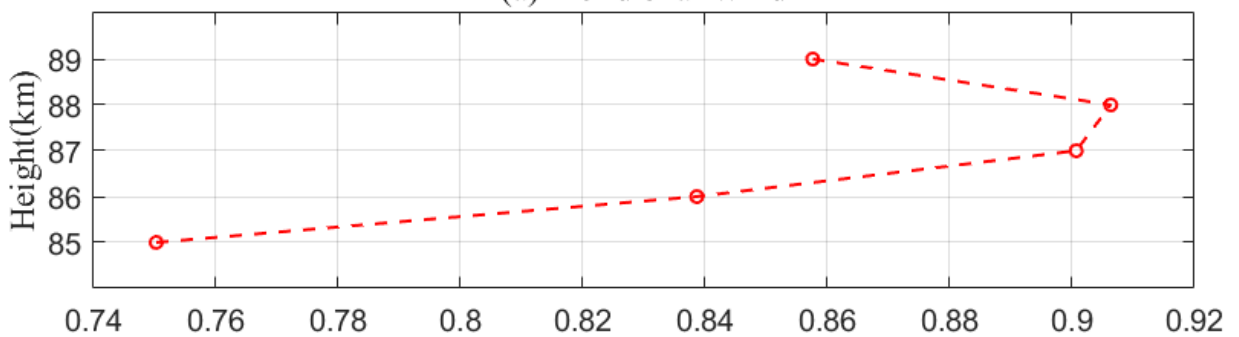

(b) Zonal Wind

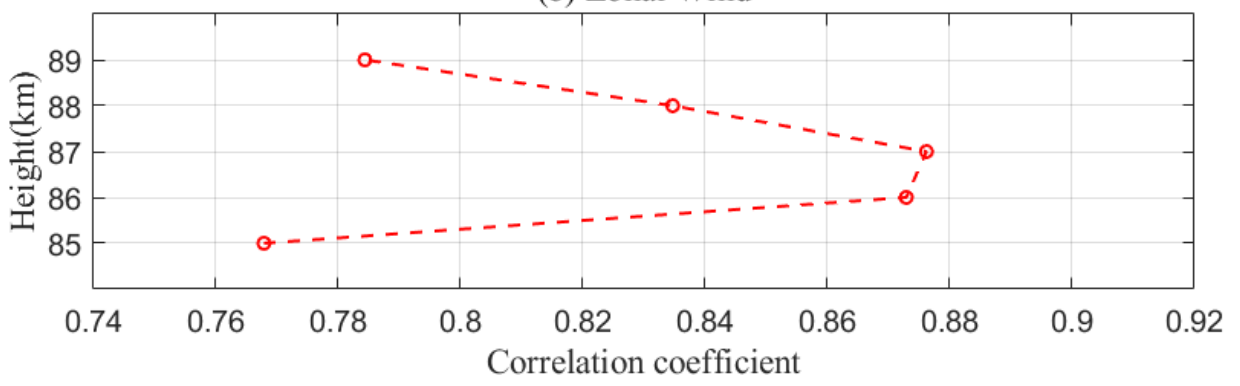

Figure 6. The correlation coefficients between the observation results of FPI 892.0-nm wavelength airglow and meteor radar at 85, 86, 87, 88, and $89 \mathrm{~km}$ for (a) meridional and (b) zonal components.

Figure 6 shows that the horizontal wind observations from the 892.0-nm OH airglow emission were most relevant to the meteor radar neutral wind observations at 87 or $88 \mathrm{~km}$. This is possibly because the 892.0 -nm airglow emissions peaked at heights between 87 and $88 \mathrm{~km}$. The SABER instrument on board the TIMED satellite can measure the $\mathrm{OH}$ emissions at two channels, $1.6 \mu \mathrm{m}$ and $2.0 \mu \mathrm{m}$ [26]. The authors of [27] pointed out that the emission peak heights of different vibration levels were different, and the bands originating from higher vibration levels had higher emission peak heights. Figure 7 shows the concentration distribution of the 1.6- and 2.0- $\mu \mathrm{m} \mathrm{OH}$ emissions on days 27 and 34, from which we can see 
that the $\mathrm{OH}$ emission at these two channels peaked between $\sim 86$ and $88 \mathrm{~km}$. The peak height of the 892.0-nm OH emission is, thus, also likely to be close to between 86 and $88 \mathrm{~km}$.
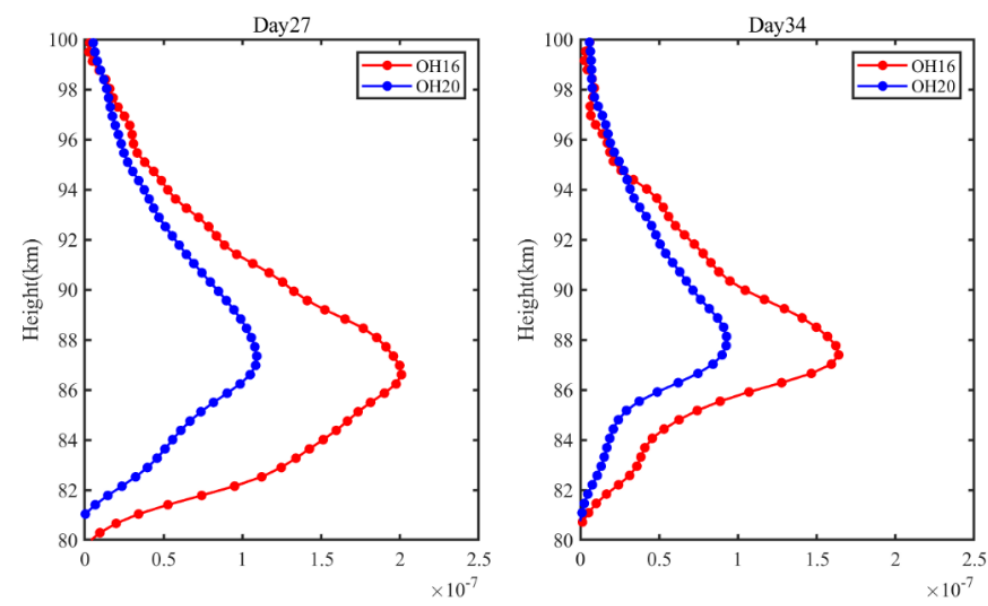

Figure 7. The vertical distribution of the 1.6- and $2.0-\mu \mathrm{m} \mathrm{OH}$ concentrations on days 27 and 34 observed by SABER instrument. The profiles nearest to Kunming are exhibited.

Considering that the neutral wind observations by ground-based FPI represent the average wind fields of the entire airglow layer, we also wanted to calculate the weighted wind values of the meteor radar horizontal wind observations. To be exact, we used the concentration of the $\mathrm{OH}$ airglow emission at every height, which is shown in Figure 7, as the weight of the wind observations from meteor radar and calculated the weighted meteor radar wind between 85 and $89 \mathrm{~km}$. Figure 8 shows the correlation coefficient between the 892.0-nm FPI wind observations and the meteor radar wind at $87 \mathrm{~km}$, the weighted meteor radar wind between 86 and $88 \mathrm{~km}$, and the weighted meteor radar wind between 85 and $89 \mathrm{~km}$, respectively. All the observations during days 26-39 were utilized in the analysis. In the meridian direction, the correlation coefficient between the FPI wind and meteor radar wind increased from 0.90 to 0.92 when all the $\mathrm{OH}$ airglow emissions between 85 and $89 \mathrm{~km}$ were counted. In the zonal direction, the coefficient between the 892.0-nm FPI observations and the weighted wind speed of the meteor radar between 85 and $89 \mathrm{~km}$ is $\sim 0.89$ also showed an increase compared with the correlation coefficient between FPI observations and meteor radar observations at $87 \mathrm{~km}$. This clearly showed that the neutral winds of the entire $\mathrm{OH}$ emission layer all contributed to the ground-based FPI wind observations, but the wind at the $\mathrm{OH}$ peak height accounted for most of the ground-based observations. The FPI observations are thus presentative for the neutral wind at $\sim 87 \mathrm{~km}$.
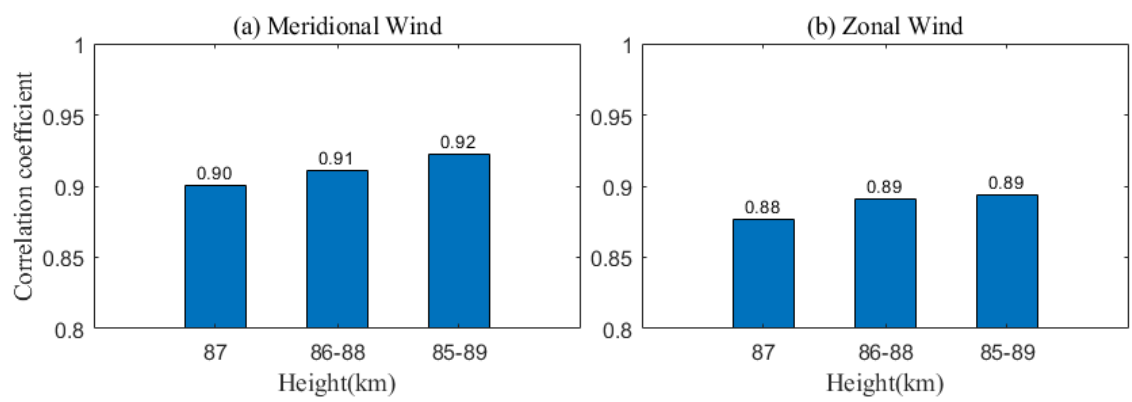

Figure 8. Correlation coefficients between FPI neutral wind and original meteor radar winds at $87 \mathrm{~km}$, weighted meteor winds between 86 and $88 \mathrm{~km}$, and weighted meteor radar winds between 85 and $89 \mathrm{~km}$. The (a) meridional and (b) zonal components are exhibited by Figure $8 \mathrm{a}, \mathrm{b}$, respectively.

The correlation coefficients in Figure 6 represent the temporal consistency between FPI and meteor radar wind observations, which were between $\sim 0.8$ and 0.9 for both the 
zonal and meridional components. Hereafter, we will investigate the relationship between the absolute values of FPI and meteor radar wind observations. Figure 9 shows the scatters of the FPI and meteor radar observations, as well as their linear fitting results. There was a strong linear relationship between meteor radar and FPI results, though the observation results of meteor radar were larger than that of FPI. The slope of the linear fitting was between $\sim 1.36$ and 1.33 for meteor radar meridional and zonal winds at $87 \mathrm{~km}$, respectively, which means that the meteor radar observations were $\sim 1.3$ times as great as the FPI observations. The FPI instrument measures the averaged wind values of the whole airglow layer. For example, the 892.0-nm FPI channel measures the airglow emission of $\mathrm{OH}$, which lies between 80 and $100 \mathrm{~km}$ with a peak value at $\sim 87 \mathrm{~km}$ (Figure 7). The 892.0-nm channel FPI wind observation is, thus, the averaged wind value between 80 and $100 \mathrm{~km}$, though we usually take it as the wind value at $\sim 87 \mathrm{~km}$. However, the meteor measures the wind at every vertical grid, e.g., $85 \mathrm{~km}, 86 \mathrm{~km}$, and $87 \mathrm{~km}$. The meteor radar wind observation at $87 \mathrm{~km}$ was, thus, larger than that measured by $892.0-\mathrm{nm}$ FPI channel. Nevertheless, the slopes became smaller when the weighted (by airglow emission) meteor radar winds were utilized (Figure 10). For example, the weighted meteor winds between 86 and $88 \mathrm{~km}$ were $\sim 1.35$ and $\sim 1.32$ as large as the FPI 892.0-nm observations for meridional and zonal components, respectively; the weighted meteor wind between 85 and $89 \mathrm{~km}$ was $\sim 1.31$ as large as the FPI 892.0-nm observations for both meridional and zonal components. This means that the absolute values of FPI and meteor radar observations become a bit closer when a much thicker $\mathrm{OH}$ layer is considered.
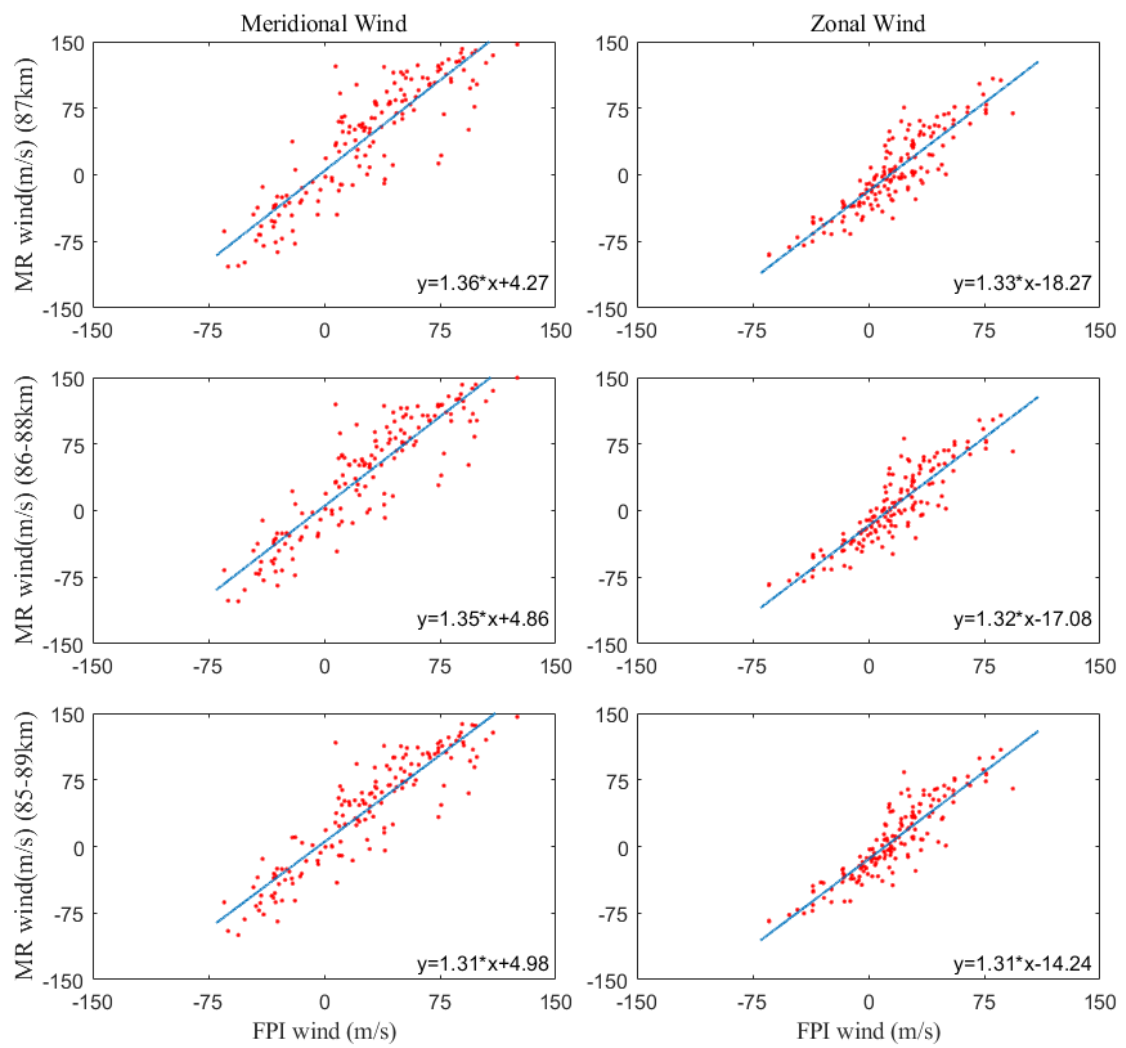

Figure 9. The scatters and linear fitting results of the FPI 892.0nm wind observations with the original meteor radar observations at $87 \mathrm{~km}$ (upper panels), the weighted meteor radar observations at between 86 and $88 \mathrm{~km}$ (middle panels), and between 85 and $89 \mathrm{~km}$ (lower panels). 

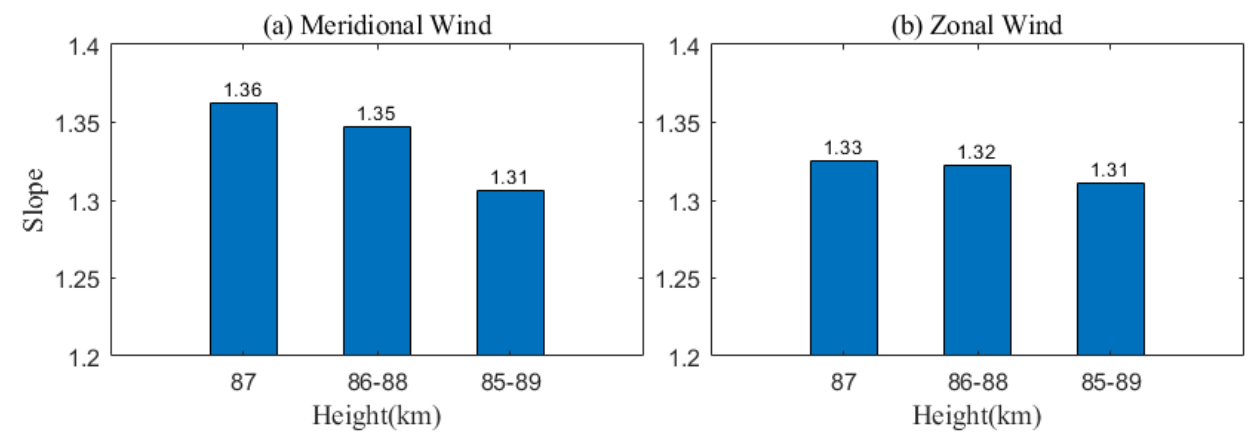

Figure 10. The slopes of the linear fitting in Figure 9 between FPI and meteor radar (a) meridional and (b) zonal wind observations.

\section{Summary}

Both FPI and meteor radar are two important ground-based pieces of equipment that can measure the neutral wind fields in the mesopause region. The FPI is a passive optical equipment, while the meteor radar is an active radio equipment. In this paper, we compared the FPI and meteor radar observations at a low-latitude observatory (Kunming $\left.\left(25.6^{\circ} \mathrm{N}, 103.8^{\circ} \mathrm{E}\right)\right)$ for the first time. Both instruments operated with good condition from 26 January to 8 February 2019, which provided an opportunity for the comparative analysis of the wind fields observed by meteor radar and FPI. The meteor radar at Kunming works at a frequency of $53.1 \mathrm{MHz}$, and could only detect meteors up to $94 \mathrm{~km}$. We, therefore, only compared the meteor radar horizontal wind observations with the FPI neutral wind observations from the 892.0-nm channel, which originates from the $\mathrm{OH}$ airglow emission and has a peak height of $\sim 87 \mathrm{~km}$ (Figure 7).

We found that the temporal variations in the FPI and meteor radar neutral wind observations generally agreed with each other, the correlation coefficients of which reached 0.90 and 0.88 at $87 \mathrm{~km}$ for meridional and zonal components, respectively. The temporal coefficients increased slightly when weighted (by $\mathrm{OH}$ airglow emission concentration) meteor radar wind fields between 85 and $89 \mathrm{~km}$ were utilized in the correlation analysis. For example, the correlation coefficients between FPI and weighted meteor radar meridional (zonal) winds between 86 and $88 \mathrm{~km}$ and 85 and $89 \mathrm{~km}$ reached $0.91(0.89)$ and $0.92(0.89)$, respectively.

Furthermore, we compared the absolute values of the FPI and meteor radar wind observations. Our analysis results showed that the neutral winds from these two instruments had a strong linear relationship, though the meteor radar observations were larger than those of the FPI observations. To be exact, the meteor radar wind at $87 \mathrm{~km}$ was 1.36 and 1.33 times as large as the FPI observations for the meridional and zonal components, respectively. Nevertheless, the slopes of the linear fitting decreased to $\sim 1.31$ for the weighted meteor radar wind observations between 85 and $89 \mathrm{~km}$ for both meridional and zonal winds. This means that the absolute values of the weighted winds of meteor radar become closer to the FPI observations.

The temporal variations in the meteor radar and the FPI wind observations, as well as the comparison between their absolute values, showed that these two instruments give consistent mesospheric wind observations. The neutral wind at the $\mathrm{OH}$ peak height contributed most to the 892.0-nm FPI observations. The FPI and meteor radar wind observations at an Antarctic observatory $\left(62.22^{\circ} \mathrm{S}, 58.79^{\circ} \mathrm{W}\right)$ showed that the meteor radar was between 1.2 and 1.4 times as large as the FPI wind observations at the $\mathrm{OH}$ emission peak height [20]. Our current analysis regarding the comparison between FPI and meteor radar observations at low latitude in the Northern Hemisphere contributes significantly to the comprehensive comparison between these two instruments. The FPI could measure the neutral wind fields in the mesosphere and lower and upper thermosphere $(\sim 87 \mathrm{~km}, \sim 97 \mathrm{~km}$, and $\sim 250 \mathrm{~km}$ ) continuously, which facilitates the study of the lower-upper atmospheric 
coupling. The validation of FPI observation with other instruments contributes greatly to the popularization of FPI instrument in the future.

Author Contributions: Conceptualization, S.G.; methodology, W.Y. and G.H.; formal analysis, X.H.; resources, Z.D., N.L., and J.C.; writing—original draft preparation, S.G. and X.H.; supervision, X.D. All authors have read and agreed to the published version of the manuscript.

Funding: This research work was supported by the National Natural Science Foundation of China (41704153, 41874181, and 41831071).

Institutional Review Board Statement: Not applicable.

Informed Consent Statement: Not applicable.

Data Availability Statement: The data presented in this study are available on request from the corresponding author (S. G., gushengyang@whu.edu.cn). The data are not publicly available due to institutional restriction.

Conflicts of Interest: The authors declare no conflict of interest.

\section{References}

1. Pramitha, M.; Kumar, K.K.; Ratnam, M.V.; Praveen, M.; Rao, S.V.B. Gravity Wave Source Spectra Appropriation for Mesosphere Lower Thermosphere Using Meteor Radar Observations and GROGRAT Model Simulations. Geophys. Res. Lett. 2020, 47, e2020GL089390. [CrossRef]

2. Gu, S.; Hou, X.; Qi, J.; TengChen, K.; Dou, X. Reponses of middle atmospheric circulation to the 2009 major sudden stratospheric warming. Earth Planet. Phys. 2020, 4, 1-7. [CrossRef]

3. Conte, J.F.; Chau, J.L.; Urco, J.M.; Latteck, R.; Vierinen, J.; Salvador, J.O. First Studies of Mesosphere and Lower Thermosphere Dynamics Using a Multistatic Specular Meteor Radar Network Over Southern Patagonia. Earth Space Sci. 2021, 8, e2020EA001356. [CrossRef]

4. Lee, C.; Jee, G.; Wu, Q.; Shim, J.S.; Murphy, D.; Song, I.-S.; Kwon, H.-J.; Kim, J.-H.; Kim, Y.H. Polar Thermospheric Winds and Temperature Observed by Fabry-Perot Interferometer at Jang Bogo Station, Antarctica. J. Geophys. Res. Space Phys. 2017, 122, 9685-9695. [CrossRef]

5. Wang, Y.; Milinevsky, G.; Evtushevsky, O.; Klekociuk, A.; Han, W.; Grytsai, A.; Antyufeyev, O.; Shi, Y.; Ivaniha, O.; Shulga, V. Planetary Wave Spectrum in the Stratosphere-Mesosphere during Sudden Stratospheric Warming 2018. Remote Sens. 2021, 13, 1190. [CrossRef]

6. Yasyukevich, A.; Medvedeva, I.; Sivtseva, V.; Chernigovskaya, M.; Ammosov, P.; Gavrilyeva, G. Strong Interrelation between the Short-Term Variability in the Ionosphere, Upper Mesosphere, and Winter Polar Stratosphere. Remote. Sens. 2020, $12,1588$. [CrossRef]

7. Jiang, G.; Xu, J.; Wang, W.; Yuan, W.; Zhang, S.; Yu, T.; Zhang, X.; Huang, C.; Kerr, R.B.; Noto, J.; et al. A Comparison of Quiet Time Thermospheric Winds Between FPI Observations and Model Calculations. J. Geophys. Res. Space Phys. 2018, 123, 7789-7805. [CrossRef]

8. Wu, Q.; Ward, W.; Kristoffersen, S.; Maute, A.; Liu, J. Simulation and Observation of Lunar Tide Effect on High-Latitude, Mesospheric and Lower Thermospheric Winds During the 2013 Sudden Stratospheric Warming Event. J. Geophys. Res. Space Phys. 2019, 124, 1283-1291. [CrossRef]

9. Pancheva, D.; Mukhtarov, P.; Hall, C.; Smith, A.K.; Tsutsumi, M. Climatology of the short-period (8-h and 6-h) tides observed by meteor radars at Tromsø and Svalbard. J. Atmos. Sol. -Terr. Phys. 2021, 212, 105513. [CrossRef]

10. Stober, G.; Baumgarten, K.; McCormack, J.P.; Brown, P.; Czarnecki, J. Comparative study between ground-based observations and NAVGEM-HA analysis data in the mesosphere and lower thermosphere region. Atmos. Chem. Phys. 2020, 20, 11979-12010. [CrossRef]

11. Tang, Q.; Zhou, Y.; Du, Z.; Zhou, C.; Qiao, J.; Liu, Y.; Chen, G. A Comparison of Meteor Radar Observation over China Region with Horizontal Wind Model (HWM14). Atmosphere 2021, 12, 98. [CrossRef]

12. Tian, C.; Hu, X.; Liu, Y.; Cheng, X.; Yan, Z.; Cai, B. Seasonal Variations of High-Frequency Gravity Wave Momentum Fluxes and Their Forcing toward Zonal Winds in the Mesosphere and Lower Thermosphere over Langfang, China ( $\left.39.4^{\circ} \mathrm{N}, 116.7^{\circ} \mathrm{E}\right)$. Atmosphere 2020, 11, 1253. [CrossRef]

13. Luo, J.; Gong, Y.; Ma, Z.; Zhang, S.; Zhou, Q.; Huang, C.; Huang, K.; Yu, Y.; Li, G. Study of the Quasi 10-Day Waves in the MLT Region During the 2018 February SSW by a Meteor Radar Chain. J. Geophys. Res. Space Phys. 2021, 126, e2020JA028367. [CrossRef]

14. Huang, K.M.; Liu, A.Z.; Lu, X.; Li, Z.; Gan, Q.; Gong, Y.; Huang, C.M.; Yi, F.; Zhang, S.D. Nonlinear coupling between quasi 2 day wave and tides based on meteor radar observations at Maui. J. Geophys. Res. Atmos. 2013, 118, 10-936. [CrossRef] 
15. Wu, Q.; Gablehouse, R.D.; Solomon, S.C.; Killeen, T.L.; She, C.-Y. A new Fabry-Perot interferometer for upper atmosphere research. In Fourth International Asia-Pacific Environmental Remote Sensing Symposium 2004: Remote Sensing of the Atmosphere, Ocean, Environment, and Space; International Society for Optics and Photonics: Bellingham, WA, USA, 2004; Volume 5660, pp. 218-227. [CrossRef]

16. Zorkaltseva Olga, S.; Vasilyev Roman, V. Stratospheric influence on the mesosphere-lower thermosphere over mid latitudes in winter observed by a Fabry-Perot interferometer. Ann. Geophys. 2021, 39, 267-276. [CrossRef]

17. Li, W.; Chen, Y.; Liu, L.; Trondsen, T.S.; Unick, C.; Wyatt, D.; Ning, B.; Li, G.; Huang, C.; Yang, S.; et al. Variations of Thermospheric Winds Observed by a Fabry-Perot Interferometer at Mohe, China. J. Geophys. Res. Space Phys. 2021, 126, e2020JA028655. [CrossRef]

18. Yu, T.; Xia, C.; Zuo, X.; Huang, C.; Mao, T.; Liu, L.; Liu, Z. A comparison of mesospheric and low-thermospheric winds measured by Fabry-Perot interferometer and meteor radar over central China. J. Geophys. Res. Space Phys. 2016, 121. [CrossRef]

19. Yu, T.; Zuo, X.; Xia, C.; Li, M.; Huang, C.; Mao, T.; Zhang, X.; Zhao, B.; Liu, L. Peak height of OH airglow derived from simultaneous observations a Fabry-Perot interferometer and a meteor radar. J. Geophys. Res. Space Phys. 2017, 122, $4628-4637$. [CrossRef]

20. Lee, C.; Jee, G.; Kam, H.; Wu, Q.; Ham, Y.B.; Kim, Y.H.; Kim, J.H. A Comparison of Fabry-Perot Interferometer and Meteor Radar Wind Measurements Near the Polar Mesopause Region. J. Geophys. Res. Space Phys. 2021, 126, e2020JA028802. [CrossRef]

21. Lee, W.; Kim, Y.H.; Lee, C.; Wu, Q. First comparison of mesospheric winds measured with a fabry-perot interferometer and meteor radar at the King Sejong Station $\left(62.2^{\circ} \mathrm{S}, 58.8^{\circ} \mathrm{W}\right)$. J. Astron. Space Sci. 2018, 35, 235-242.

22. Reid, I.M.; Holdsworth, D.A.; Morris, R.J.; Murphy, D.J.; Vincent, R.A. Meteor observations using the Davis mesospherestratosphere-troposphere radar. J. Geophys. Res. Space Phys. 2006, 111. [CrossRef]

23. Yi, W.; Xue, X.; Reid, I.M.; Younger, J.P.; Chen, J.; Chen, T.; Li, N. Estimation of Mesospheric Densities at Low Latitudes Using the Kunming Meteor Radar Together With SABER Temperatures. J. Geophys. Res. Space Phys. 2018, 123, 3183-3195. [CrossRef]

24. Holdsworth, D.A.; Reid, I.M.; Cervera, M.A. Buckland Park all-sky interferometric meteor radar. Radio Sci. 2004, 39. [CrossRef]

25. Yi, W.; Chen, J.S.; Ma, C.B.; Li, N.; Zhao, Z.W. Observation of upper atmospheric temperature by Kunming all-sky meteor radar. Chin. J. Geophys. 2014, 57, 2423-2432.

26. Kowalewski, S.; von Savigny, C.; Palm, M.; McDade, I.C.; Notholt, J. On the impact of the temporal variability of the collisional quenching process on the mesospheric $\mathrm{OH}$ emission layer: A study based on SD-WACCM4 and SABER. Atmospheric Chem. Phys. Discuss. 2014, 14, 10193-10210. [CrossRef]

27. Savigny, C.V.; McDade, I.C.; Eichmann, K.U.; Burrows, J.P. On the dependence of the $\mathrm{OH}^{*}$ Meinel emission altitude on vibrational level: SCIAMACHY observations and model simulations. Atmos. Chem. Phys. 2012, 12, 8813-8828. [CrossRef] 